Major article

\title{
Structure for prevention of health care-associated infections in Brazilian hospitals: A countrywide study
}

Maria Clara Padoveze PhD, RN, MSc ${ }^{\mathrm{a}, *}$,

Carlos Magno Castelo Branco Fortaleza MD, PhD, MSc ${ }^{b}$, Carlos Kiffer MD, PhD, MSc ${ }^{c}$, Afonso Luís Barth PhD ${ }^{\mathrm{d}}$, Irna Carla do Rosário Souza Carneiro MD, PhD, MSc ${ }^{\mathrm{e}}$, Heloisa Ilhe Garcia Giamberardino MD, MSc Jorge Luiz Nobre Rodrigues MD, PhD, MSc ${ }^{g}$, Lauro Santos Filho MD, PhD, $\mathrm{MSc}^{\mathrm{h}}$, Maria Júlia Gonçalves de Mello MD, PhD, MSc ${ }^{i}$, Milca Severino Pereira PhD, RN, MSc ${ }^{j}$, Paulo Gontijo Filho MD, PhD, MSc ${ }^{\mathrm{k}}$, Mirza Rocha MD, PhD, MSc ${ }^{1}$, Eduardo Alexandrino Servolo de Medeiros MD, PhD, MSc ${ }^{\mathrm{m}}$, Antonio Carlos Campos Pignatari MD, $\mathrm{PhD}^{\mathrm{m}}$

\footnotetext{
${ }^{a}$ Department of Collective Health Nursing, School of Nursing of University of São Paulo, São Paulo, Brazil

${ }^{\mathrm{b}}$ Department of Infectious Diseases, Botucatu School of Medicine, State University of São Paulo, Botucatu, Brazil

${ }^{c}$ Special Clinical Microbiology Laboratory, Infectious Diseases Discipline, Federal University of São Paulo, São Paulo, Brazil

${ }^{\mathrm{d}}$ Laboratory of Research in Bacterial Resistance, Center for Experimental Research, Clinical Hospital of Porto Alegre, Federal University of Rio Grande do Sul, Porto Alegre, Brazil

e Department of Infectious Diseases, Federal University of Pará, Belém do Pará, Brazil

${ }^{\mathrm{f}}$ Epidemiology and Infection Control Department, Pequeno Principe Hospital, Curitiba, Brazil

${ }^{\mathrm{g}}$ Department of Community Health, Faculty of Medicina, Federal University of Ceará, Ceará, Brazil

${ }^{\mathrm{h}}$ Clinical Microbiology Discipline, Federal University of Paraíba, João Pessoa, Brazil

${ }^{\mathrm{i}}$ Hospital Infection Control Committee, Instituto de Medicina Integral Prof. Fernando Figueira, Recife, Brazil

${ }^{\mathrm{j}}$ Department of Nursing, Pontifical Catholic University, Goias, Brazil

${ }^{\mathrm{k}}$ Microbiology, Biomedical Sciences Institute, Uberlândia Federal University, Uberlândia, Brazil

${ }^{1}$ Núcleo de Vigilância Hospitalar, Instituto Nacional de Saúde da Mulher, da Criança e do Adolescente Fernandes Figueira, Fundação Oswaldo Cruz, Rio de Janeiro, Brazil

${ }^{\mathrm{m}}$ Division of Infectious Diseases, Federal University of São Paulo, São Paulo, Brazil
}

Key Words:

Hospital infections

Infection control

Public health

Hand hygiene

Sterilization

Hospital infection control program
Background: Minimal structure is required for effective prevention of health care-associated infection (HAI). The objective of this study was to evaluate the structure for prevention of HAI in a sample of Brazilian hospitals. Methods: This was a cross-sectional study from hospitals in 5 Brazilian regions $(n=153$; total beds: 13,983) classified according to the number of beds; 11 university hospitals were used as reference for comparison. Trained nurses carried out the evaluation by using structured forms previously validated. The evaluation of conformity index $(\mathrm{CI})$ included elements of structure of the Health Care-Associated Prevention and Control Committee (HAIPCC), hand hygiene, sterilization, and laboratory of microbiology. Results: The median $\mathrm{CI}$ for the HAIPCC varied from 0.55-0.94 among hospital categories. Hospitals with $>200$ beds had the worst ratio of beds to sinks (3.9; $P<.001)$. Regarding alcoholic product for handrubbing, the worst ratio of beds to dispensers was found in hospitals with $<50$ beds (6.4) compared with reference hospitals $(3.3 ; P<.001)$. The $\mathrm{CI}$ for sterilization services showed huge variation ranging from $0.0-1.00$. Reference hospitals were more likely to have their own laboratory of microbiology than other hospitals.

\footnotetext{
* Address correspondence to Maria Clara Padoveze, PhD, RN, MSc, School of Nursing of University of São Paulo. Av. Dr. Enéas de Carvalho Aguiar, 419, São Paulo São Paulo, Brazil, CEP 05.403-000.

E-mail address: padoveze@usp.br (M.C. Padoveze).

Previous presentation: Presented in part at the International Conference on Prevention and Infection Control, June 2013, Geneva, Switzerland.
}

Funding/Support: Supported by the National Council for Scientific and Technological Development (CNPq: 563225/2010-6) in partnership with the Ministry of Health of Brazil, under the call MCT/CNPq/CT-Saúde/MS/SCTIE/DECIT N 40/2010.

Conflicts of interest: None to report. 
Conclusion: This study highlights the need for public health strategies aiming to improve the structure for HAI prevention in Brazilian hospitals.

Copyright $\odot 2016$ by the Association for Professionals in Infection Control and Epidemiology, Inc. Published by Elsevier Inc. All rights reserved.

A minimal structure is required for effective prevention of health care-associated infection (HAI), mainly the presence of an active Health Care-Associated Infection Prevention and Control Committee (HAIPCC). ${ }^{1}$ Appropriate resources for hand hygiene, medical devices sterilization, and microbiologic analysis of clinical specimens are also among the core components of a good structure for HAI prevention and control. ${ }^{2}$ Developing countries have higher HAI rates compared with developed nations, mainly because of their lack of resources and scarcity of expertise in epidemiology and infection control. ${ }^{3}$ This raises an important concern regarding patient safety worldwide; therefore, high priority should be given for infection prevention strategies in low and middle-income countries. ${ }^{3,4}$

In the last decade, Brazil has experienced a significant improvement in its socioeconomic condition. However, until now, there has been a lack of information regarding the structure for prevention of HAI in hospitals within country. The knowledge of the actual structure for HAI prevention in Brazilian hospitals will support public policies aiming at overcoming deficiencies and defining priorities. To fulfill this need, a national study was proposed to identify the main features of HAI prevention resources in the country with a multidisciplinary team of researchers, called Project IRAS-Brazil. This study aimed to evaluate the structure for prevention of HAI in a sample of Brazilian hospitals.

\section{MATERIALS AND METHODS}

\section{Design and settings}

A cross-sectional study was carried out from August 2011August 2013. Hospitals located in the 5 Brazilian regions were evaluated.

\section{Sampling}

A list of all acute care hospitals in the country was obtained from the free-access national database of health care facilities (CNES: http://cnes.datasus.gov.br/). The sample size included 10 out of 26 Brazilian states (Ceará, Goiás, Minas Gerais, Pará, Paraná, Paraíba, Pernambuco, Rio Grande do Sul, Rio de Janeiro, and São Paulo). These states were selected by convenience; nevertheless, they host about two-thirds of all health care facilities within the country. A cluster sampling technique was used, and clusters were defined by state and number of hospital beds. The hospitals were chosen at random in the study base (from the 10 states) within 3 categories according to the number of beds: $10-49$ beds, 50-199 beds, and $\geq 200$ beds. Eleven university hospitals which harbored the teams that conducted the study were included by convenience and were used as reference for comparison purposes.

\section{Data collection}

Teams of nurses experienced in infection control were trained to carry out the evaluation by using structured forms previously validated. ${ }^{5}$ They visited each one of the randomized facilities and reference hospitals and performed the evaluation through direct observation, inspection of documents, and interviews. Written guidelines were developed to avoid dissimilarities in data collection procedures. For each state under investigation, a coordinator hosted in the reference hospitals was in charge to manage operational issues of data collection and to ensure homogeneity along the investigation procedures. Evaluation was focused on 4 essential areas: HAIPCC, sterilization service (SS), hand hygiene resources, and laboratory of microbiology. These areas were selected considering their impact in HAI prevention. Each area was evaluated according to their main components: for HAIPCC, components included operational structure, guidelines, HAI surveillance, and activities for preventions. For SS, components included cleaning, preparing-wrapping, and sterilization-storage. Hand hygiene resources included structural conditions for handwashing and antiseptic handrubbing with alcohol. The ratio of beds to sinks, beds to alcohol dispensers, patients to sinks, and patients to alcohol dispensers was calculated counting the resources available at the point of care. Elements of functionality and cleanliness of hand hygiene resources were also evaluated. Laboratories of microbiology were only visited if they were located within hospital premises; the 10 following components were evaluated: human resources, technical guidelines, management programs, environmental structure, decontamination and waste, automation, culture media and water quality, quality control, susceptibility tests, and typing procedures. Each component was further detailed in several elements to be evaluated. Elements were evaluated in regard to their presence, with no attempt to further evaluate their quality details. A conformity index (CI) was composed by the overall sum of elements in a given area to be evaluated, and the final $\mathrm{CI}$ was considered as the proportion of the number of elements which were in conformity in a given component evaluated. A CI of $\geq 0.75$ (or $75 \%$ ) was considered a good level of quality in structure for infection prevention and control.

A summary of data collection tool is available on request from the author.

\section{Statistics}

The databank was fed in each state and sent by electronic means to a central coordination located in São Paulo, where data consolidation and analysis were performed.

The 11 university hospitals were used as reference when performing comparison among categories. The rationale of choosing these hospitals as reference was not related to the excellence in infection prevention, but rather to the presence of well-established infection control teams with tradition in research in this field. Spearman coefficient $(\rho)$ was used to identify correlation in the $\mathrm{CI}$ among the components evaluated. Linear regression models were used to identify correlations between the CI (dependent variables) and hospital categories and country regions (independent variables). Mid- $P$ correction of the Fisher exact test was used for comparison of ratio of sinks or alcohol dispensers per patients or beds. In all tests, significance was assumed if $P<.05$. Statistics tests were performed using OpenEpi (Emory University, Atlanta, GA), Epi Info 3.5 (Centers for Disease Control and Prevention, Atlanta, GA), and SPSS 19.0 (IBM, Armonk, NY).

\section{Ethics}

The research project was approved by the Committee of Ethical Research of the Federal University of São Paulo (protocol no. 0119/ 
Table 1

Distribution of the number of hospitals, total number of beds, and median beds per hospital (range) according to the hospital categories, Brazil, 2011-2013

\begin{tabular}{|c|c|c|c|}
\hline $\begin{array}{l}\text { Hospital Category/ } \\
\text { Region }\end{array}$ & Hospitals (n) & Total no. of beds & $\begin{array}{l}\text { Median beds per } \\
\text { hospital (range) }\end{array}$ \\
\hline Reference & 11 & 4,747 & $462(144-984)$ \\
\hline Southeast & 4 & 1,298 & $486(144-812)$ \\
\hline Northeast & 3 & 1,476 & $250(242-984)$ \\
\hline Midwest & 1 & 302 & 302 (NA) \\
\hline North & 1 & 377 & 377 (NA) \\
\hline South & 2 & 1,294 & $647(641-653)$ \\
\hline$\geq 200$ beds & 8 & 2,247 & $280(223-386)$ \\
\hline Southeast & 5 & 1,398 & $286(234-316)$ \\
\hline Northeast & 1 & 386 & 386 (NA) \\
\hline Midwest & 0 & NA & NA (NA) \\
\hline North & 1 & 223 & 223 (NA) \\
\hline South & 1 & 240 & 240 (NA) \\
\hline $50-199$ beds & 55 & 4,910 & $79(50-181)$ \\
\hline Southeast & 22 & 1,902 & $74(51-181)$ \\
\hline Northeast & 10 & 997 & $99(50-159)$ \\
\hline Midwest & 3 & 237 & $83(66-88)$ \\
\hline North & 3 & 281 & $96(70-115)$ \\
\hline South & 17 & 1,493 & $77(60-165)$ \\
\hline$<50$ beds & 79 & 2,079 & $24(10-49)$ \\
\hline Southeast & 31 & 894 & $30(10-49)$ \\
\hline Northeast & 5 & 177 & $30(10-40)$ \\
\hline Midwest & 22 & 526 & $21(10-42)$ \\
\hline North & 6 & 188 & $25(10-49)$ \\
\hline South & 15 & 294 & $24(10-33)$ \\
\hline Total & 153 & 13,983 & $45(10-984)$ \\
\hline
\end{tabular}

$N A$, not applicable.

11) and by board committees from all of the other 10 reference hospitals.

\section{RESULTS}

The distribution of the number of hospitals and beds among the sample is shown in Table 1. The intended sample was 270 hospitals (6.8\% of all hospitals in the studied states; $4.3 \%$ of the total number in Brazil). However, there was sample loss for the following reasons: (1) relevant incongruity between CNES (official registry) data and actual hospital data (type of health care facility did not fit the inclusion criteria; inexistence of health care facility, lack of inpatient units, or other); (2) no answer from the hospital to the research team after $\geq 3$ contact attempts; (3) refusal to participate; (4) refusal or lack of signature in the official ethical form approval; and (5) difficulties in hospital access because of geographic reasons (no road access; regional flood at the time of data collection). Public hospitals comprised $73 \%$ of the reference hospitals, $75 \%$ of the large hospitals ( $>200$ beds), 33\% of the medium-sized hospitals (50-199 beds), and $38 \%$ of the small hospitals ( $<50$ beds). The other remaining hospitals were private or not-for-profit, and most of them were partially dependant on public funding.

\section{HAI Prevention and Control Committee}

We found a large variation in the CI for the HAIPCC. Smaller hospitals had a lower CI compared with reference hospitals $(P<.001)$ (Table 2). Regional diversity influences this variation; the Midwest region was most likely to have a poor CI in their HAIPCC. Taking into account the hospital categories and regions, we found that the South and Southeast regions were more likely to have a better $\mathrm{CI}$ when compared with the others. Smaller hospitals had a significantly lower $\mathrm{CI}$ regardless of the region (Table 2). The lack of professionals dedicated to the HAIPCC was one of the most frequent flaws observed in smaller hospitals. Written guidelines for essential issues on infection prevention, such as those for germicides
Table 2

Distribution of percentiles of the conformity index for the Health Care-Associated Infection Prevention and Control Committee and $P$ values (linear regression) according to categories of hospitals and geographic region $(n=153)$, Brazil, 2011-2013

\begin{tabular}{|c|c|c|c|c|c|c|c|}
\hline & Minimum & $25 \%$ & $50 \%$ & $75 \%$ & Maximum & $\begin{array}{c}\text { Crude } \\
P \text { value }\end{array}$ & $\begin{array}{l}\text { Adjusted } \\
P \text { value* }\end{array}$ \\
\hline \multicolumn{8}{|c|}{ Hospital category } \\
\hline $\begin{array}{l}\text { Reference } \\
\text { hospitals }\end{array}$ & 0.69 & 0.90 & 0.94 & 0.98 & 1.00 & Reference & Reference \\
\hline$\geq 200$ beds & 0.67 & 0.95 & 0.96 & 0.99 & 1.00 & .20 & .90 \\
\hline $50-199$ beds & 0.06 & 0.70 & 0.88 & 0.96 & 1.00 & $<.001$ & .09 \\
\hline$<50$ beds & 0.00 & 0.23 & 0.55 & 0.84 & 1.00 & $<.001$ & $<.001$ \\
\hline \multicolumn{8}{|l|}{ Country region } \\
\hline Southeast & 0.00 & 0.67 & 0.88 & 0.95 & 1.00 & Reference & Reference \\
\hline Northeast & 0.00 & 0.33 & 0.76 & 0.94 & 1.00 & .07 & .001 \\
\hline Midwest & 0.00 & 0.23 & 0.43 & 0.64 & 0.98 & $<.001$ & .001 \\
\hline North & 0.00 & 0.15 & 0.76 & 0.95 & 1.00 & .09 & .04 \\
\hline South & 0.00 & 0.60 & 0.85 & 0.97 & 1.00 & .90 & .90 \\
\hline
\end{tabular}

*Adjusted $P$ value to country region and hospital category.

${ }^{\dagger}$ Eleven university hospitals.

standardization and use, environmental cleaning, and devices sterilization, were not found in most hospitals. Routine surveillance activities were demonstrated; nevertheless, surprisingly, many HAIPCCs did not use the national standard definitions (CI variation among hospital categories: $0.40-0.89$ ), and most hospitals actually did not base their preventive efforts on the surveillance data (CI variation among hospital categories: 0.37-0.74). The preventive activities were usually well documented regarding wards, intensive care, and neonatal care but are poorly documented regarding other services, such as emergence departments, blood donation, and laboratories (CI variation among hospital categories: 0.23-0.94). The worst $\mathrm{CI}$ for each component was observed in hospitals with $<50$ beds. We detected positive correlations in the CI among all 4 components of the HAIPCC $(P<.001)$. We observed slightly smaller values of $\rho$ regarding the component of HAI prevention activities compared with other components (Fig 1).

\section{Sterilization services}

Overall, SSs showed low CIs, with best results in hospitals with $\geq 200$ beds. Among those with $<50$ beds, the $\mathrm{CI}$ found was $<0.70$, up to percentile $75 \%$, which may be considered a worrisome situation for this category of hospitals. The best CIs for SS were observed in the regions of the Southeast $(\mathrm{CI}=0.64$, at percentile $50 \%)$ and South $(\mathrm{CI}=0.71$, at percentile $50 \%)(P<.003)$, but in this case, it does not matter the category of hospital. Both cleaning and preparing-wrapping components have shown lower CIs compared with the sterilization-storage component, mainly in smaller hospitals. Positive correlation was found among CIs observed in the 3 components evaluated. We also identified overall positive correlation for the CI between HAIPCC and SS ( $\rho=0.669 ; P<.001)$ (Table 3).

\section{Hand hygiene}

The ratios of hand hygiene resources per bed and per inpatient are demonstrated in Table 4. Poor CI for sinks means that even when present, sinks and other resources for hand hygiene lacked functionality or cleanliness (Table 4).

\section{Microbiology laboratories}

The final sample corresponded to $90.9 \%$ of laboratories in reference hospitals and $21.1 \%$ of other remaining hospitals categories because these health care settings were mainly supported by outsourced laboratories, which could not be evaluated. Among 

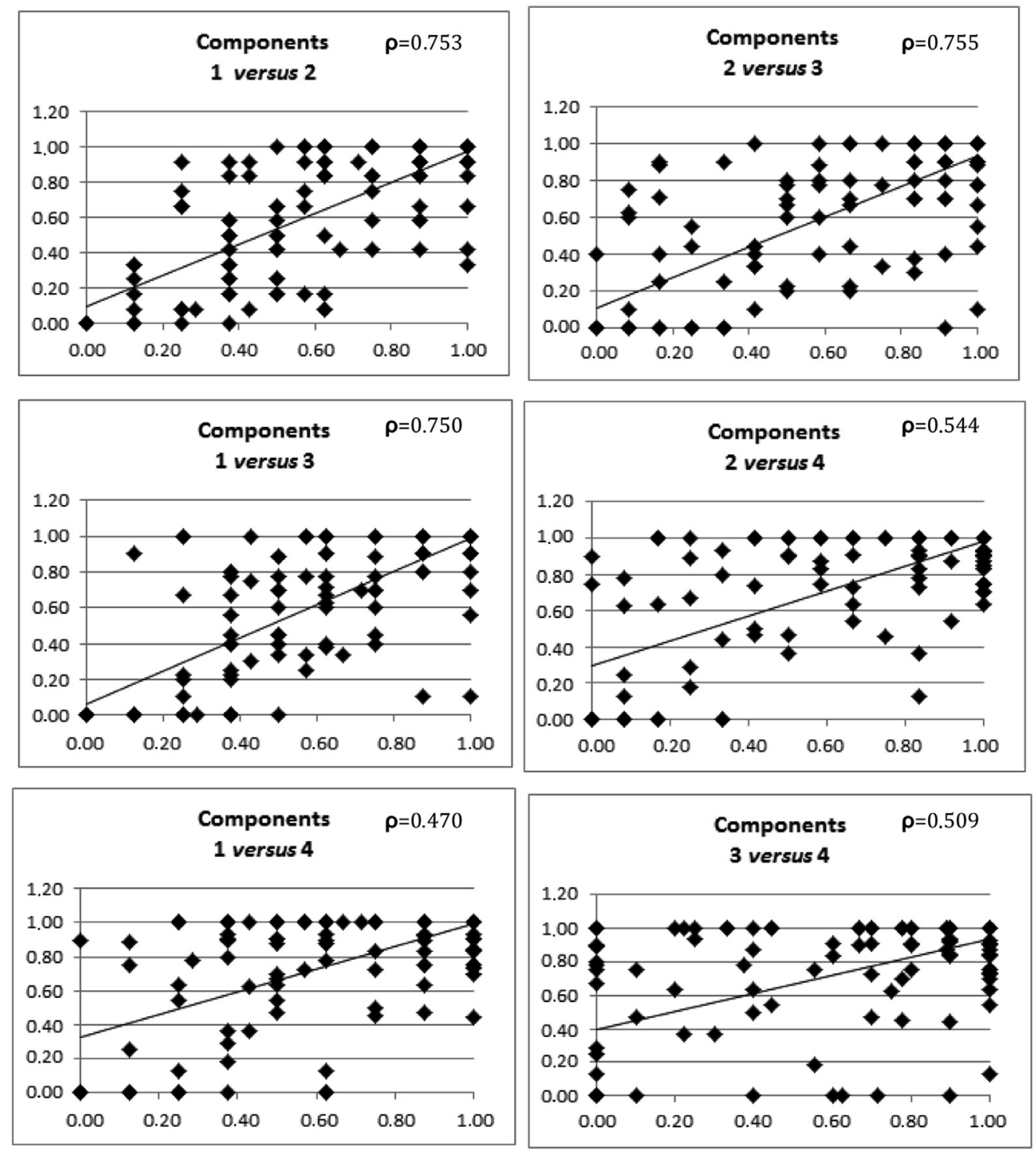

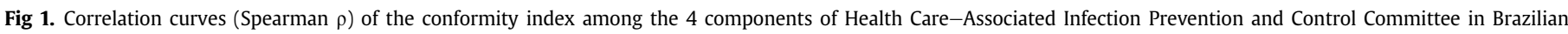

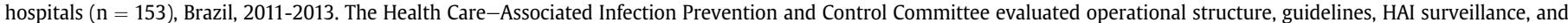

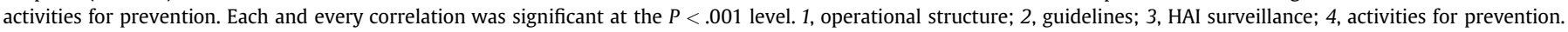

laboratories visited, the CI ranged from 0.30-0.87. The quality control for culture media, such as Muller-Hinton, showed to have the worst conformity $(\mathrm{CI}=0.30)$, followed by the quality control for other culture media and water $(\mathrm{CI}=0.42)$.

\section{DISCUSSION}

Brazil is a highly populated country (192 million) with approximately 6,266 hospitals (2012 data) spread in a large territory, posing a challenge to countrywide studies aiming at driving governmental strategies for prevention and control of HAI. ${ }^{6}$ To our knowledge, this study presents the first scaled evaluation of structure for HAI prevention in the country.

Despite being mandatory by law since $1997,{ }^{7}$ the HAIPCC is still not fully compliant with all legal and recommended issues. This is particularly true for smaller hospitals, both public and private, which may deal with lack of economic support to provide even minimal resources for HAI prevention. We believe economic issues may account significantly for the very poor $\mathrm{CI}$ of SSs among smaller hospitals because physical structure, equipment, instruments, and supplies are usually expensive. This is an even more stringent situation regarding localities outside the Southeast and South regions. Of note, the index of human development is higher in states in the Southeast and South regions (United Nations Development Program: http://www.pnud. org.br).

The detection of such variation in HAI prevention structure at hospitals is intimately linked to the Brazilian health care system model, which provides a certain level of autonomy to the states. ${ }^{6}$ The Brazilian Unified Health System works at the municipal, state, and federal levels by direct management or by agreements or contracts with private health care units. For its part, the private sector (supplementary health care services) organizes itself by health care plans or by direct reimbursement of health care costs to the users. First, this raises questions about the efficiency and safety of small-sized hospitals ( $<50$ beds) in the country. These types of hospitals represent $62 \%$ of hospital units, accounting for approximately $18 \%$ of beds in the Brazilian health care system. ${ }^{8}$ In many 
Table 3

Distribution of percentiles of the conformity index for sterilization services and $P$ values (linear regression) according to categories of hospitals and geographic region ( $\mathrm{n}=153)$, Brazil, 2011-2013

\begin{tabular}{|c|c|c|c|c|c|c|c|}
\hline & Minimum & $25 \%$ & $50 \%$ & $75 \%$ & Maximum & $\begin{array}{c}\text { Crude } \\
P \text { value }\end{array}$ & $\begin{array}{l}\text { Adjusted } \\
P \text { value* }\end{array}$ \\
\hline \multicolumn{8}{|c|}{ Hospital category } \\
\hline $\begin{array}{c}\text { Reference } \\
\text { hospital }^{\dagger}\end{array}$ & 0.51 & 0.58 & 0.63 & 0.79 & 0.92 & Reference & Reference \\
\hline$\geq 200$ beds & 0.48 & 0.56 & 0.80 & 0.91 & 0.99 & .50 & .50 \\
\hline $50-199$ beds & 0.00 & 0.54 & 0.74 & 0.86 & 0.99 & .90 & .50 \\
\hline$<50$ beds & 0.00 & 0.37 & 0.51 & 0.64 & 0.95 & .01 & .005 \\
\hline \multicolumn{8}{|l|}{ Country region } \\
\hline Southeast & 0.30 & 0.56 & 0.64 & 0.82 & 0.99 & Reference & Reference \\
\hline Northeast & 0 & 0.34 & 0.56 & 0.76 & 0.87 & .02 & .002 \\
\hline Midwest & 0.20 & 0.36 & 0.45 & 0.53 & 0.76 & $<.001$ & $<.001$ \\
\hline North & 0 & 0.29 & 0.49 & 0.56 & 0.99 & .008 & .003 \\
\hline South & 0 & 0.54 & 0.71 & 0.85 & 0.97 & .60 & .50 \\
\hline
\end{tabular}

*Adjusted $P$ value to country region and hospital category.

'Eleven university hospitals.

\section{Table 4}

Ratio of beds to sinks, patients to sinks, beds to alcoholic product dispensers, and patients to alcoholic product dispensers and the conformity index in Brazilian hospitals $(\mathrm{n}=153)$, Brazil, 2011-2013

\begin{tabular}{|c|c|c|c|c|c|c|}
\hline Hospital category & $\begin{array}{c}\text { Beds to } \\
\text { sinks* }\end{array}$ & $\begin{array}{c}\text { Patients } \\
\text { to sinks }\end{array}$ & $\mathrm{CI}$ & $\begin{array}{l}\text { Beds to } \\
\text { alcoholic } \\
\text { product } \\
\text { dispensers }\end{array}$ & $\begin{array}{l}\text { Patients }^{\dagger} \\
\text { to alcoholic } \\
\text { product } \\
\text { dispensers }\end{array}$ & $\mathrm{CI}$ \\
\hline Reference hospital $^{\ddagger}$ & 3.34 & 2.54 & 0.65 & 3.27 & 2.47 & 0.83 \\
\hline$\geq 200$ beds & $3.91^{\S}$ & $3.12^{\S}$ & $0.59^{8}$ & 3.49 & 2.79 & 0.84 \\
\hline 50-199 beds & 3.14 & $2.01^{\S}$ & $0.50^{8}$ & 3.39 & $2.17^{5}$ & $0.75^{8}$ \\
\hline$<50$ beds & 3.08 & $1.47^{8}$ & $0.43^{\S}$ & 6.43 & $3.06^{\S}$ & $0.76^{8}$ \\
\hline
\end{tabular}

$\mathrm{CI}$, conformity index, which includes elements of functionality and cleanliness of hand hygiene resources.

*Includes all resources for handwashing: sinks, soap, and paper towels.

${ }^{\dagger}$ Number of inpatients at the moment of visiting for evaluation.

Eleven university hospitals.

${ }^{\S} \mathrm{P}<.05$.

situations, small-sized hospitals are filling the gap of a deficient primary care system, with more than half of them the only option for inpatient treatment in many municipalities. ${ }^{8}$ As a consequence, most of these hospitals have low complexity of care. Therefore, it seems irrational to spend technologic resources, such as surgical equipment and invasive devices, instead of concentrating them in larger reference hospitals. Second, there is an urgent need for strong investments at the state level to improve the structure for HAI prevention. In a similar political system regarding the autonomy of states, in 2009 the United States designated $\$ 40$ million for the Centers for Diseases Control and Prevention to support states. ${ }^{9}$ Along with this initiative, all states were required to take their amount of responsibility in the prevention chain, including dealing with epidemiologic data and actions plans to promote HAI reduction. $^{9}$

We did not explore in deep detail the time dedication or qualifications for infection control preventionists related to their activities as others researchers did. ${ }^{10-12}$ That type of research could help understand the reasons for the HAIPCC failing to use their own data to drive the infection control program because it could be related to difficulties to deal with epidemiologic information. As previously mentioned, many infection preventionists only work as data collectors and do not move toward leadership for improvement intervention. ${ }^{13}$ Most importantly, the primary purpose of surveillance is reducing nosocomial infections at the hospital level; therefore, the use of data must be greatly beyond providing information to the Brazilian authorities.
A few studies evaluated the structure for HAI prevention in groups of hospitals by means of using criteria inspired or adapted from the Study on the Efficacy of Nosocomial Infection Control project. In general, those studies looked mainly at infection control personnel, prevention activities, and surveillance. ${ }^{10,12,14-17}$ The use of a mailed or electronic questionnaire was more frequent than in locus visiting. ${ }^{10-12,15-18}$ A Korean study also included the evaluation of resources for hand hygiene, ${ }^{11,14}$ but they only evaluated hospitals with $>300$ beds. Others tried to identify the influence of characteristics and size of hospitals with adverse events rates or issues of the HAI program, with heterogeneous results. ${ }^{10,19,20}$

The results from this study showed that the HAIPCC tend to have a balanced level of compliance between the 4 main components of the program. The findings that hospitals that are more compliant with HAIPCC tend to have also high compliant SSs may be explained by the mutual influence between nurses in SSs and the HAIPCC. Simply, this also can only reflect an overall quality of the hospital or accreditation status, ${ }^{5,16,17}$ which was not the focus of our study.

Brazilian regulations determine the use of alcoholic product at the point of care. ${ }^{21}$ However, as demonstrated in other studies, the infrastructure for hand hygiene is not fully implemented. ${ }^{22}$

Besides this, our data reinforce the information from a previous Brazilian study regarding the weakness of structure and process of laboratories of microbiology linked to hospitals. ${ }^{23}$

A major strength of our study was the on-site collection of data carried out by trained personnel, minimizing bias and contributing to greater accuracy of the survey. This was implied in an enormous effort from the research team to provide operational and logistic background for all of these visits. The comparison of the reference hospitals with other categories has highlighted differences that may be useful when defining public policies applicable not only in Brazil but in other developing countries with similar characteristics. Among the limitations of our study, we should point out the infeasibility of including all 26 states in our sample. The selection of 10 states was a relevant pragmatic decision taking into consideration operational difficulties to perform such a study in Brazil, which is a federative nation with large geographic dimensions and limited resources. These states harbored 3,964 hospitals in 2012, corresponding to $63.3 \%$ of all hospitals in Brazil. Even though Brazil has many differences among regions, states in a same region are relatively homogeneous. Although randomization was used, several hospitals declined to participate in the evaluation, which may have introduced bias in our study. Furthermore, during the data collection, we found difficulties to get undoubted information regarding the number of professionals enrolled in the directed health care assistance.

\section{CONCLUSIONS}

The findings from this study have major implications in national policies in promoting patient safety. A national plan should be driven to strengthen the main structures in HAI prevention, HAIPCC, SS, and laboratories of microbiology, giving high priority for the Midwest, North, and Northeast regions.

\section{Acknowledgments}

The Research Group of the Project IRAS-BRASIL acknowledges the efforts from nurses that contributed with data collection and thank the cooperation of the health care team in the visited hospitals. 


\section{References}

1. Scheckler WE, Brimhall D, Buck AS, Farr BM, Friedman C, Garibaldi RA, et al Requirements for infrastructure and essential activities of infection control and epidemiology in hospitals: a consensus panel report. Society for Healthcare Epidemiology of America. Am J Infect Control 1998;26:47-60.

2. World Health Organization. Core components for infection prevention and control programmes: Report of the Second Meeting Informal Network on Infection Prevention and Control in Health Care. Geneva, Switzerland; 26-27 June 2008. Geneva: WHO; 2009.

3. Allegranzi B, Bagheri Nejad S, Combescure C, Graafmans W, Attar H, Donaldson L, et al. Burden of endemic health-care-associated infection in developing countries: systematic review and meta-analysis. Lancet 2011;377: 228-41.

4. Pittet D, Allegranzi B, Storr J, Bagheri Nejad S, Dziekan G, Leotsakos A, et al. Infection control as a major World Health Organization priority for developing countries. J Hosp Infect 2008;68:285-92.

5. Silva CP, Lacerda RA. Validation of a proposal for evaluating hospital infection control programs. Rev Saude Publica 2011;45:121-8.

6. Padoveze MC, Castelo Branco Fortaleza CM. Healthcare-associated infections: challenges to public health in Brazil. Rev Saude Publica 2014;48:995-1001.

7. Brasil. Lei no. 9.431, de 06 de Janeiro de 1997. Dispõe sobre a obrigatoriedade de manutenção de programas de controle de infecção hospitalar pelos hospitais do país. Brasília: Diário Oficial da União; 1997.

8. Ugá M, López E. Small hospitals and their insertion in Brazil's National Health System (SUS). Cien Saude Colet 2007:12:915-28.

9. Srinivasan A, Craig M, Cardo D. The power of policy change, federal collaboration, and state coordination in healthcare-associated infection prevention. Clin Infect Dis 2012;55:426-31.

10. Stone PW, Dick A, Pogorzelska M, Horan TC, Furuya EY, Larson E. Staffing and structure of infection prevention and control programs. Am J Infect Control 2009;37:351-7.

11. Oh HS, Chung HW, Kim JS, Cho SI. National survey of the status of infection surveillance and control programs in acute care hospitals with more than 300 beds in the Republic of Korea. Am J Infect Control 2006;34:223-33.

12. Nguyen GT, Proctor SE, Sinkowitz-Cochran RL, Garrett DO, Jarvis WR. Status of infection surveillance and control programs in the United States, 1992-1996. Association for Professionals in Infection Control and Epidemiology, Inc. Am J Infect Control 2000;28:392-400.
13. Murphy D, Carrico R, Warye K. Building the infection prevention system of tomorrow: proceedings of the 2007 APIC Futures Summit. Am J Infect Control 2008;36:232-40

14. Oh HS, Cheong HW, Yi SE, Kim H, Choe KW, Cho SI. Development and application of evaluation indices for hospital infection surveillance and contro programs in the Republic of Korea. Infect Control Hosp Epidemiol 2007;28: 435-45.

15. Sanchez-Paya J, Bischofberger C, Lizan M, Lozano J, Munoz Platon E, Navarro J, et al. Nosocomial infection surveillance and control: current situation in Spanish hospitals. J Hosp Infect 2009;72:50-6.

16. Sekimoto M, Imanaka Y, Kobayashi H, Okubo T, Kizu J, Kobuse H, et al. Impac of hospital accreditation on infection control programs in teaching hospitals in Japan. Am J Infect Control 2008;36:212-9.

17. Sekimoto M, Imanaka Y, Kobayashi H, Okubo T, Kizu J, Kobuse H, et al. Factors affecting performance of hospital infection control in Japan. Am J Infect Control 2009;37:136-42

18. Fakih MG, Heavens M, Ratcliffe CJ, Hendrich A. First step to reducing infection risk as a system: evaluation of infection prevention processes for 71 hospitals. Am J Infect Control 2013;41:950-4.

19. Arroyo A, Ramirez JM, Callejo D, Vinas X, Maeso S, Cabezali R, et al. Influence of size and complexity of the hospitals in an enhanced recovery programme for colorectal resection. Int J Colorectal Dis 2012;27:1637-44.

20. Ou L, Chen J, Assareh H, Hollis SJ, Hillman K, Flabouris A. Trends and variations in the rates of hospital complications, failure-to-rescue and 30-day mortality in surgical patients in New South Wales, Australia, 2002-2009. PLoS One 2014;9: e96164.

21. ANVISA. Agência Nacional de Vigilância Sanitária. Resolução RDC n. 42, de 25 de outubro de 2010. Dispõe sobre a obrigatoriedade de disponibilização de preparação alcoólica para fricção antisséptica das mãos, pelos serviços de saúde do País, e dá outras providências. Available from: http://bvsms.saude. gov.br/bvs/saudelegis/anvisa/2010/res0042_25_10_2010.html. Accessed September 15, 2015.

22. Struelens MJ, Wagner D, Bruce J, MacKenzie FM, Cookson BD, Voss A, et al. Status of infection control policies and organisation in European hospitals, 2001: the ARPAC study. Clin Microbiol Infect 2006;12:729-37.

23. Costa LB, Cardoso MR, Ferreira CG, Levy CE, Borba HM, Sallas J, et al. National prevalence survey in Brazil to evaluate the quality of microbiology laboratories: the importance of defining priorities to allocate limited resources. Rev Panam Salud Publica 2013;33:73-8. 